\title{
India en el marco de la pandemia: impactos a su status de potencia emergente
}

\author{
India in the Pandemic: The Impacts on its Status as an Emerging Power \\ María Noel Dussort
}

María Noel Dussort es docente e investigadora de la Escuela de Relaciones Internacionales, Universidad Nacional de Rosario, Argentina.

E-mail: maria.dussort@fcpolit.unr.edu.ar

\section{resumen}

La pandemia por Covid-19 sorprendió al mundo. El impacto de la enfermedad fue crítico y de evolución rápida en algunos países de Europa (España, Italia, Alemania, Gran Bretaña, entre otros) y Asia-Pacífico (Corea del Norte, Nueva Zelanda, Japón), y provocó una crisis sanitaria nunca antes vista en el mundo contemporáneo. No obstante, en los países en desarrollo de Asia del Sur, África y América Latina, el crecimiento del número de casos comenzó siendo lento y aparentemente controlado. A medida que transcurrieron los meses, el centro neurálgico del aumento de los casos se trasladó a estos países en desarrollo. India ejemplifica el rumbo que tomó el efecto contagio del Covid-19 a nivel global. La pregunta que ha mantenido en vilo a quienes estudiamos este país ha sido la siguiente: ¿cómo controlar la expansión de una enfermedad altamente contagiosa, en la segunda nación más populosa del mundo y en el contexto de profundas carencias socioeconómicas? El objetivo de este trabajo es analizar la evolución de la pandemia en India y las medidas que su gobierno ha tomado para enfrentar esta "nueva normalidad". Asimismo, se consideran los impactos que dicha crisis pueda generar en su categoría de potencia emergente en un orden internacional en transición.

\section{summary}

The Covid-19 pandemic shocked the world. The impact of the disease was critical and it has evolved fast in some developed countries of Europe (Spain, Italy, Germany, Great Britain, among others) and Asia (North Korea, New Zealand, Japan), causing a health crisis never seen before in the contemporary world. However, the growth in the number of cases in developing countries of South Asia, Africa and Latin America started slowly and apparently controlled. However, as months went by, developing countries have seen the increase in number of cases surpassing the aforementioned developed ones. India exemplifies the course that the contagion effect of Covid-19 has taken globally. The question that arises in those of us who study this country is how to control the spread of a highly contagious disease, in the second most populous nation in the world and in a context of deep socioeconomic deficiencies? The objective of this essay is to analyse the evolution of the pandemic in India and the measures its government has taken to face this "new normal". In addition, it is considered the impacts that this crisis may have on India's category of emerging power in a transition to a new international order.

\section{palabras clave}

India / pandemia / potencia emergente / impactos

\section{keywords}

India / pandemic / emerging power / impacts 
La pandemia por Covid-19 sorprendió al mundo. Si bien, en los inicios, la enfermedad pareció circunscribirse a una región de China, pronto alcanzó los confines del mundo más alejados de la zona cero. Los primeros casos de este virus comenzaron en 2019, aunque no fue hasta el 11 de marzo de 2020 que la Organización Mundial de la Salud (OMS) declaró el estado de pandemia a nivel internacional. Para muchos, se trató una respuesta tardía, que ha direccionado las más severas críticas a China, por no haber puesto en alerta a la Organización tiempo antes.

Más allá de las numerosas y variopintas teorías conspirativas que se han esbozado a lo largo de estos once meses en busca de culpables o chivos expiatorios, los datos nos muestran que, en un primer momento, el impacto de la enfermedad fue crítico y de una evolución rápida en algunos países desarrollados de Europa (España, Italia, Alemania, Gran Bretaña, entre otros) y Asia-Pacífico (Corea del Norte, Nueva Zelanda, Japón), y que provocó una crisis sanitaria nunca antes vista en el mundo contemporáneo. Por su parte, en los países en desarrollo de Asia del Sur, África y América Latina, el crecimiento del número de casos comenzó siendo lento y aparentemente controlado. Sin embargo, y a medida que fueron transcurriendo los meses, el centro neurálgico del aumento sostenido de los casos se encuentra en estas naciones en desarrollo.

India ejemplifica el rumbo que ha tomado el efecto contagio del Covid-19 a nivel global. El primer caso que se registró en este país fue a finales del mes de enero en el estado de Kerala, situado en el extremo suroeste del país. Se trató de una persona que arribó en un vuelo proveniente de la ciudad de Wuhan, China. Desde entonces, la pregunta que ha mantenido en vilo a quienes nos dedicamos al estudio de India ha sido la siguiente: ¿cómo controlar la expansión de una enfermedad altamente contagiosa, en la segunda nación más populosa del mundo y en el contexto de profundas carencias socioeconómicas estructurales?

\section{Evolución de la pandemia y medidas tomadas por el gobierno indio}

La primera medida del gobierno de Narendra Modi fue la declaración de la cuarentena estricta el 24 de marzo de 2020, para lo cual se aplicó el aislamiento obligatorio a aproximadamente 1300 millones de habitantes. Esta decisión generó desorganización y caos en megalópolis como Nueva Delhi, situación que fue contenida a través de la represión de las fuerzas policiales. Ello se debió a una combinación de factores: en primer lugar, la falta de previsión del gobierno frente a un sector informal que alcanza el $80 \%$ del total de la población económicamente activa y que, frente al anuncio de la declaración de cuarentena sin previo aviso, miles de personas pasaron a quedar desempleadas. ${ }^{1}$ En segundo lugar, gran parte de ese sector está compuesto por trabajadores migrantes, que se trasladan desde el sector rural a la ciudad en busca de oportunidades laborales. En tanto, frente a la restricción de la circulación, se impidió que pudieran retornar a sus hogares para poder cumplir con el aislamiento social. El resultado fue que miles de personas quedaron varadas en las estaciones de autobuses en condiciones de hacinamiento, a la espera de una respuesta, situación que podría haber tenido efectos catastróficos. 
No obstante, la evolución de los contagios en India al comienzo fue lenta. De hecho, desde marzo hasta mediados de junio de 2020, el país asiático contabilizaba poco más de 300 mil casos y aproximadamente 8 mil muertes. Sin embargo, desde ese momento hasta la fecha -14 de agosto de 2020, momento en que se escribe este ensayo-, la curva de contagios se aceleró rápidamente, y suma una media de 60 mil casos diarios. En la actualidad, es el tercer país con mayor cantidad de contagios del mundo, luego de Estados Unidos y Brasil, y contabiliza 2 millones 500 mil infectados y 48 mil muertes. Es ineludible la coincidencia temporal entre el aumento de infectados y la flexibilización de la cuarentena, a partir del $1^{\circ}$ de junio. Dicha apertura gradual de actividades se ha llevado a cabo en diferentes etapas (unlock 1.0, 2.0 y 3.0 en junio, julio y agosto respectivamente). Se admitió, en un primer momento, el movimiento irrestricto de bienes y personas entre estados, el retorno a las oficinas, la apertura de lugares religiosos, hoteles, centros comerciales, restaurantes y servicios hospitalarios no dedicados a la atención de pacientes Covid-19. ${ }^{2}$ De todos modos, se mantuvo el toque de queda desde las 9pm hasta las $5 \mathrm{am}$, así como la cuarentena estricta para determinadas "zonas de contención", es decir, áreas con gran número de contagios. A partir de agosto, hubo un nuevo cambio, al contemplar la apertura de gimnasios y centros de yoga, y se revocó el toque de queda.

En base a la evolución de los datos, el director del Centro de Biología Molecular y Celular de Hyderabad (CCMB, por sus siglas en inglés), Rakesh Mishra, afirmó que la nación india aún no ha alcanzado el pico de casos. Esto implica que la situación probablemente empeore y quizás sobrepase a Brasil y Estados Unidos. Interesa destacar que, si bien el brote comenzó en ciudades densamente pobladas como Nueva Delhi o Bombay, en la actualidad se ha extendido a pequeños poblados rurales, donde los infectados son muy difíciles de detectar.

En este marco, se debe tener presente que India carece de una infraestructura sanitaria para afrontar una pandemia de estas características. Según un informe reciente de la OCDE, el panorama del sector salud pre-Covid presentaba los siguientes números: el país poseía una media de 0,5 camas hospitalarias por cada mil habitantes, el gasto sanitario por persona era de 2,5 dólares anuales y había un déficit de personal capacitado (médicos y enfermeras). A ello se suma que el porcentaje de testeos comenzó siendo muy bajo. Hasta inicios del mes de junio, se habían hecho tan solo un millón de hisopados, lo cual representa menos del 1\% de la población. A su vez, se registran largas demoras en la comunicación de los resultados, lo que provoca que gran parte de las personas posiblemente infectadas eviten el cumplimiento del distanciamiento social correspondiente.

A modo de poder afrontar esta situación, el gobierno de India solicitó un préstamo al Banco Mundial, el cual aprobó el desembolso de dos millones de dólares en calidad de asistencia financiera -entre abril y mayo-, para ser destinados al sector sanitario y a los sectores sociales más vulnerables (este último, bajo la denominación “Accelerating India's COVID-19 Social Protection Response Program"). Esto se debe a que la aplicación de la cuarentena tuvo un gran impacto negativo en la economía del país, con pérdidas que alcanzaron los dos tercios de la activi- 
dad. Los sectores mayormente afectados han sido el comercio, el transporte y la construcción. Asimismo, ha tenido severas consecuencias en pequeñas y medianas empresas, con efectos colaterales en las cadenas de suministro y distribución. La tasa de desempleo se ha incrementado de forma preocupante, no solo a nivel urbano sino también rural.

Frente a estos hechos alarmantes, el gobierno introdujo una serie de medidas de apoyo fiscal a través del Banco de Reservas de India, equivalentes al 10\% del PBI. El primer paquete de medidas fue implementado a finales de marzo de 2020 y estuvo dirigido a afrontar la emergencia sanitaria y destinado a grupos sociales vulnerables. En este sentido, se realizaron transferencias de dinero en efectivo a más de 200 millones de mujeres rurales y 30 millones de hombres y mujeres de la tercera edad y minusválidos; se entregaron bolsones de alimentos a más de la mitad de la población, así como cobertura de seguros médicos al personal de la salud. El segundo paquete de medidas fue anunciado a mediados de mayo, y se extendieron las transferencias de dinero y la entrega de alimentos a los trabajadores migrantes internos del país, así como los subsidios para desempleados rurales. Al mismo tiempo, se aplicaron medidas para reducir el estrés financiero y facilitar el acceso al financiamiento para micro, pequeñas y medianas empresas, trabajadores rurales, vendedores callejeros, entre otros.

Por otra parte, el Primer ministro Narendra Modi anunció reformas estructurales en el sector laboral y agrícola. También permitió el ingreso de compañías privadas en sectores estratégicos, con el fin de alentar la inversión. En síntesis, el objetivo central del gobierno fue inyectar liquidez, mejorar al acceso al crédito y otorgar moratorias para contener en el corto plazo las consecuencias del stop económico.

\section{Los impactos de la crisis mundial en India y su categoría de potencia emergente}

A inicios del siglo XXI, India comenzó a ser categorizada como una potencia emergente por la academia especializada en Relaciones Internacionales debido a que reunía una serie de requisitos macroeconómicos -crecimiento económico sostenido, cantidad de reservas extranjeras, participación en el comercio internacional, entre otros-, lo cual, sumado a su rol de liderazgo regional, le permitió a este país adquirir mayor influencia y protagonismo internacional. Al mismo tiempo, ampliaba su activismo internacional en diferentes foros de negociación mundial como OMC, G20, IBSA, BRICS, BASIC, entre otros.

Ahora bien, la pandemia, por un lado, redundó en un impacto negativo en algunas de las características que hacen a su conceptualización de potencia emergente y podría repercutir en el ascenso que ha conseguido en los últimos veinte años en la jerarquía internacional. Por otro lado, esta situación también ha abierto ventanas de oportunidad para este país de Asia del Sur, que le permitirán seguir proyectándose mundialmente. En este sentido, analizarmos brevemente tres variables y las consecuencias que han tenido desde marzo a la fecha: crecimiento económico y consumo de energía, cuidado del medioambiente y política exterior. 
En cuanto al crecimiento económico, India fue uno de los países que pudo sortear la onda expansiva producida por la crisis financiera internacional de $2008 \mathrm{y}$ que continuó creciendo luego de 2014, año en el que se registró por primera vez una retracción importante en la economía china y los demás países miembros del Foro BRICS. No obstante, desde 2016 a 2019, las cifras han sido preocupantes para el gobierno de Narendra Modi -reelecto en 2019- debido a que se ha pasado de un crecimiento anual del $8 \%$ a uno del $5 \%$, a causa de la disminución del consumo y la inversión internos. Por esta razón, a inicios de 2020, el gobierno anunció el propósito de convertir la nación en una economía de 5 billones de dólares, aunque para lograrlo se necesitaba, en ese momento, un crecimiento promedio de un $10 \mathrm{u}$ $11 \%$. La pandemia por coronavirus vino a echar por tierra esas ambiciones. Justamente, el impacto que describimos con anterioridad produjo que, por primera vez en varios años, India finalice el tercer trimestre del año fiscal en recesión.

De cualquier manera, no todas son malas noticias para las cuentas del Estado. De hecho, la contracción en el precio internacional del petróleo experimentada desde inicios de 2020 debido a las discrepancias entre Estados Unidos, Arabia Saudita y Rusia se profundizó con la pandemia. Este acontecimiento favoreció a India, dado que es el tercer mayor consumidor de energía y petróleo del mundo, y posee una alta dependencia externa de este recurso estratégico, al importar cerca del $80 \%$ de su consumo total. En abril, Nueva Delhi comenzó a aprovechar los precios bajos para estoquear 32 millones de toneladas de petróleo crudo a un 50\% menos de su valor, lo cual tuvo un impacto positivo en el déficit fiscal. De esta forma, al aumentar sus reservas estratégicas de petróleo, ha podido mejorar su seguridad energética ante una posible disrupción futura en el mercado.

En relación con la variable medioambiental, el detenimiento de las actividades en todos los sectores económicos y la reducción del tráfico vehicular comprobaron la mejora en la calidad del aire y de los ríos en India. De acuerdo con la Junta Central de Control de Contaminación india, durante los primeros días de la cuarentena se detectó una reducción de un $40 \%$ en los niveles de contaminación del aire en algunas ciudades. El resultado fue que Nueva Delhi o Bombay mostraron un paisaje completamente diferente, libres del smog que las caracteriza. Un dato alarmante que demuestra el alto grado de contaminación atmosférica fue el hecho de que por primera vez en treinta años se pudieron observar las cumbres del Himalaya, cadena montañosa que se encuentra a 160 kilómetros. Estos registros son una prueba más de que India necesita profundizar sus políticas domésticas hacia una transición energética que implique la generación de energía limpia y sustentable. El mayor desafío será el reemplazo del carbón como fuente de generación de energía eléctrica, así como la alta densidad de transporte a base de hidrocarburos.

Finalmente, cabe destacar el alto perfil del gobierno de Modi en algunos foros multilaterales. Su performance nos demuestra la continuidad del activismo internacional aún en un contexto desfavorable, y las oportunidades que se han presentado para el desarrollo de su política exterior. A modo de ejemplo, podemos mencionar, en primer lugar, la elección del Ministro de Salud de India como presi- 
dente de la Junta Ejecutiva de la Organización Mundial de la Salud el 22 de mayo de 2020. Es interesante considerar que el presidente de la Junta es elegido por sus miembros y es nominado por los comités regionales. Es decir, la candidatura del país asiático se realizó por el Comité del Sudeste de Asia. Por lo tanto, este logro diplomático resulta importante debido a la valorización positiva que los países vecinos tienen de India, lo cual afianza su liderazgo subregional. Además, India se posicionó como un país comprometido y responsable con la organización frente a otros países, cuyos líderes han amenazado con retirarse de la OMS, como en los casos de Estados Unidos y Brasil. En último lugar, la presidencia de la Junta Ejecutiva se logró en un contexto de sucesivas críticas a la Organización internacional, a la cual se considera bajo la influencia de China.

A nivel regional, India ha sabido aprovechar el momento para continuar fortaleciendo su imagen en Asia del Sur. En este sentido, en el marco de la Asociación del Sur de Asia para la Cooperación Regional (SAARC, por sus siglas en inglés), India promovió la creación de un fondo conjunto de emergencia para contener la pandemia, y con ello se convirtió en el mayor aportante.

En tercer lugar, cabe destacar el acercamiento entre Estados Unidos e India, lo cual le valió la invitación de Donald Trump para participar de la próxima reunión del $\mathrm{G}^{3}$, junto a Rusia, Corea del Sur y Australia. Este acontecimiento generó la inmediata reacción del gobierno chino, que, a través de su vocero, manifestó que cualquier intento de dibujar un círculo en contra de Beijing está condenado al fracaso y a convertirse en impopular. Si bien hay fuerzas profundas que explican el enfrentamiento armado entre China e India en la frontera territorial compartida ${ }^{4}$, no se puede dejar de interpretar este hecho como un efecto de demostración por parte de Beijing de su creciente poderío regional y global, quince días después de la extensión de la invitación del presidente estadounidense.

A modo de cierre, es indudable que, una vez que el mundo haya superado la pandemia, habrá un movimiento tectónico en el balance de poder mundial. La tendencia es que India continúe con su política exterior de multialineamiento, en un juego pragmático entre China, Estados Unidos y Rusia, para poder contribuir a su mayor objetivo nacional, es decir, alcanzar el desarrollo económico.

Lo cierto es que el manejo de las variables antes mencionadas no es una tarea fácil para ningún hacedor político, y menos aún para una democracia de 1300 millones de habitantes, de los cuales 200 millones viven en la pobreza (lo que equivale a cuatro veces la población de Argentina). Es por ello que continúa resonando la consigna "Quedate en casa" en un país donde una gran parte de la población no tiene las condiciones estructurales para hacerlo. Esta frase, nacida en los países desarrollados y adoptada por la narrativa mundial, resulta una imposición clasista que solo puede ser cumplida por aquellos que viven en condiciones dignas -vivienda, acceso a servicios básicos como agua, luz, gas, internet- y que, al mismo tiempo, pueden mantenerse "económicamente activos y productivos", ya que cuentan con los medios comunicacionales para hacerlo. El resto afronta una cruda realidad de desempleo, pobreza, vulnerabilidad biológica y estructural y falta de acceso a la información. 
Mientras se escriben estas líneas, escuchamos con esperanza el desarrollo de una vacuna que nos ayude a enfrentar esta enfermedad. Se trata de un descubrimiento que también es objeto de la disputa de poder mundial y que, sin lugar a dudas, contribuirá a las nuevas definiciones en el tablero de ajedrez mundial.

\section{Referencias}

1. Por ejemplo, los vendedores ambulantes, los tiradores de rickshaws, los conductores de tuk-tuk, entre muchos otros.

2. Es importante considerar que, más allá de dicha apertura gradual, determinadas actividades continuaron suspendidas, tales como el uso de metros, los cines, los gimnasios, la enseñanza en todos los niveles -inicial, primario, medio y universitario-y las actividades masivas de toda índole. Asimismo, los individuos que se trasladaran por razones laborales debían utilizar la aplicación móvil desarrollada por el gobierno, Aarogya Setu -su traducción al castellano es "puente de salud"-, como forma de control de síntomas y de mantener a la población informada sobre las medidas aplicadas.

3. La invitación se realizó a inicios de junio de 2020 y la cumbre del G7 estaba planificada para realizarse en septiembre de ese año.

4. El 15 de junio de 2020, fuerzas armadas de ambos países se enfrentaron en Ladakh, con un resultado de veinte soldados indios fallecidos. La zona se encuentra en disputa desde 1960 y hacía más de cuarenta años que no se producía un evento de estas características.

\section{Fuentes}

Ministry of Health and Family Welfare, Government of India https://www.mohfw.gov.in/(Consultado el 17 de agosto de 2020).

OCDE (2020). India - OECD Economic Forecast Summary (June 2020). Disponible en: https://www. oecd.org/economy/india-economic-snapshot/ (Consultado el 10 de junio de 2020).

World Bank (2020). \$1 Billion from World Bank to Protect India's Poorest from COVID-19 (Coronavirus). 14/05/2020. Disponible en: https://www.worldbank.org/en/news/press-release/2020/05/13/ world-bank-covid-coronavirus-india-protect-poor (Consultado el 17 de agosto de 2020).

María Noel Dussort, "India en el marco de la pandemia: impactos a su status de potencia emergente". Revista Temas y Debates. ISSN 1666-0714, año 24, número especial, julio-diciembre 2020, pp. 487-493. 